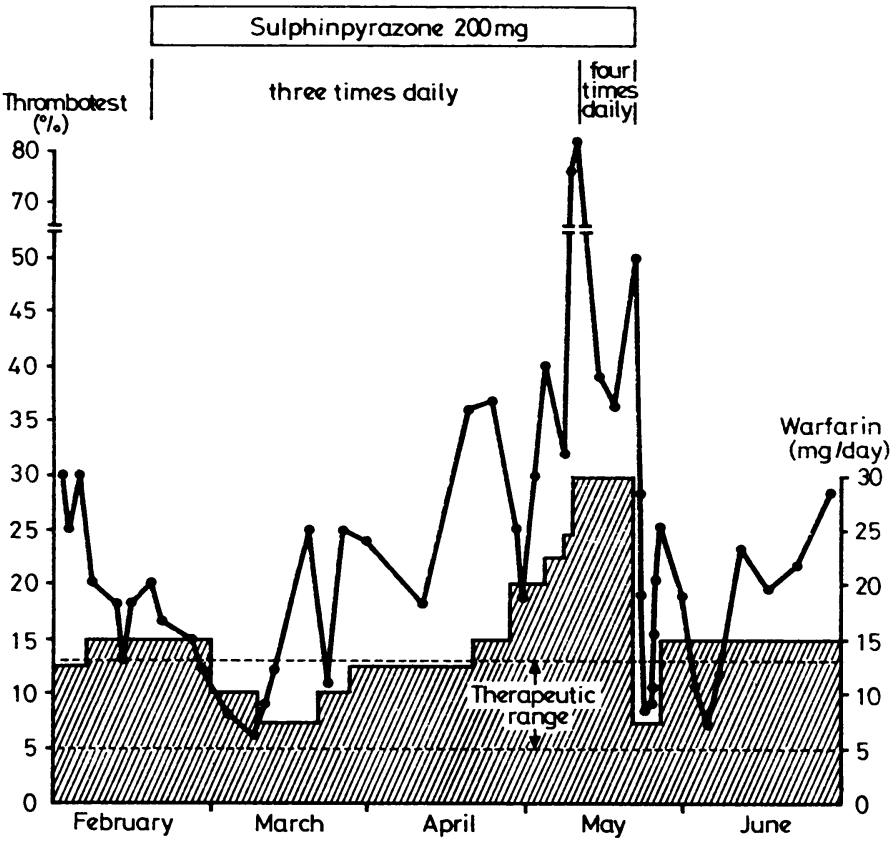

Warfarin requirement (shaded area) and results of Thrombotest (-O) before, during, and after treatment with sulphinpyrazone.

between sulphinpyrazone and warfarin. An alternative explanation might be that the potentiating effect of sulphinpyrazone disappeared because of a self-induction of its own metabolism. This was not the case, however, in our patient because the dosage of warfarin required after prolonged administration of sulphinpyrazone was far above the pretreatment dosage and returned to that value only when sulphinpyrazone was stopped.

The problems of this drug interaction are of considerable clinical interest because of the increasing use of sulphinpyrazone in patients with various cardiovascular diseases.

Requests for reprints should be addressed to Professor Giuseppe G Nenci, Director, Istituto di Semeiotica Medica, Università di Perugia, Policlinico Monteluce, 06100 Perugia, Italy.

${ }^{1}$ Davis JM, Johns LE Jr. Possible interaction of sulfinpyrazone with coumarins. N Engl f Med 1978;299:955.

${ }^{2}$ Gallus A, Birkett D. Sulphinpyrazone and warfarin: a probable drug interaction. Lancet $1980 ; \mathrm{i}: 535-6$.

${ }^{3}$ Steele PP, Weily HS, Genton E. Platelet survival and adhesiveness in recurrent venous thrombosis. N Englf Med 1973:286:1148-52.

4 Morrelli HF, Melmon KL. Drug interaction. In: Melmon KL, Morrelli HF, eds. Clinical pharmacology. New York: Macmillan, 1978:982-1007.

5 Seiler K, Duckert F. Properties of 3-(1-phenyl-propyl)-4-oxycoumarin (marcoumar) in the plasma when tested in normal cases and under the influence of drugs. Thrombosis et Diathesis Haemorrhagica 1968; 79:389-96.

(Accepted 9 February 1981)

Institutes of Semeiotica Medica and Clinica Medica, University of Perugia Medical School, Policlinico Monteluce, 06100 Perugia, Italy

GIUSEPPE G NENCI, MD, professor of medicine

GIANCARLO AGNELLI, MD, assistant professor

MAURO BERRETTINI, MD, research assistant

\section{Acute ulceration of ileal stoma due to Campylobacter fetus subspecies jejuni}

Campylobacter fetus subspecies jejuni causes acute diarrhoea, with or without fever, and occasionally dehydration. We describe a patient, previously operated on for Crohn's disease, with severe watery excretion from an ileal stoma and pronounced acute ulceration of the stoma due to Campylobacter jejuni.
Case report

A 45-year-old man underwent proctocolectomy in 1976 for Crohn's? disease and remained symptom free for three years. Three days after eating chicken he became ill with fever and severe watery diarrhoea from his stomac (4-5 1 daily) and lost $4 \mathrm{~kg}$. On admission four days later he appeared ill, with a temperature of $37.4^{\circ} \mathrm{C}$ and signs of mild dehydration. The rather large stoma was dark red, oedematous, and with large serpiginous ulcers near the tip (figure). Biopsy specimens showed acute inflammatory changes of the

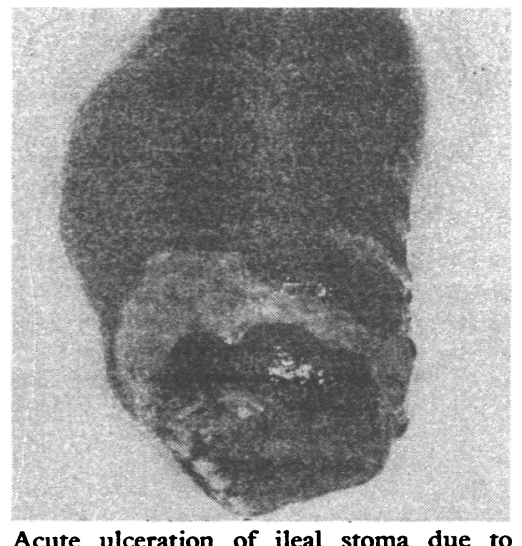

Acute ulceration of ileal stoma due

mucosa and oedema. No granulomas or giant cells were observed. Campylo-o bacter jejuni was repeatedly isolated from the stoma efflux. With rehydration the patient recovered in seven days and was discharged when the stomal $N$ efflux had returned to normal. Antibiotics were not prescribed during the admission. Cultures for Campylobacter became negative after three weeks. The stoma healed very slowly; four weeks after discharge ulcers had disappeared but residual oedema was still present. One year later he had $\overrightarrow{0}$ remained symptom free.

\section{Comment}

Little information is available on the mucosal alterations of the ileum after campylobacter infections, and most studies have dealt with changes in the colon. Loss of vascular pattern, granularity, friability, $\mathbb{Q}$ and mucosal haemorrhages are seen,,${ }^{1-3}$ and occasionally macroscopic $\Rightarrow$ ulcers have been reported.4 Our patient showed severe mucosalo abnormalities with definite ulceration around the tip of the stoma. The acute ileitis associated with sudden onset of diarrhoea and fever made an acute relapse of Crohn's disease unlikely. Our study confirms, however, that when acute enteric symptoms occur in patients with inflammatory bowel disease campylobacters should be sought. ${ }^{5}$

In our patient the clinical symptoms disappeared quickly, but. campylobacters in the stomal efflux and the abnormalities of the 3 mucosa remained for some weeks. No antibiotics were given; in retrospect, however, we think that the striking ulcerative lesions would probably have healed faster had Campylobacter jejuni been eradicated sooner.

1 Lambert ME, Schofield PF, Ironside AG, Mandal BK. Campylobacterô colitis. Br Med $\mathcal{A} 1979$;i:857-9. colitis. Br Med $\mathcal{F}$ 1979;i:857-9.
1979;32:986-9.

3 Duffy MC, Benson JB, Rubin SJ. Mucosal invasion in campylobacter enteritis. Am $\mathcal{f}$ Clin Pathol 1980;73:706-8.

4 Loss RW, Mangla JC, Pereira M. Campylobacter colitis presenting as inflammatory bowel disease with segmental colonic ulcerations. Gastro enterology 1980;79:138-40.

5 Neuman A, Lambert JR. Campylobacter jejuni causing flare-up in inflammatory bowel disease. Lancet 1980;ii:919.

(Accepted 6 February 1981)

Department of Internal Medicine, Division of Gastroenterology, University Hospital Binnengasthuis, Grimburgwal 10, 1012 GA Amsterdam, the Netherlands

S G M MEUWISSEN, MD, gastroenterologist (present address: Freen University Hospital, de Boelelaan 1117, 1007 MB Amsterdam, theo Netherlands)

P J M BAKKER, MD, physician

P I G M RIETRA, MD, bacteriologist 